\title{
Reactive oxygen species generators affect quality parameters and apoptosis markers differently in red deer spermatozoa
}

\author{
Felipe Martínez-Pastor ${ }^{1}$, Eduardo Aisen ${ }^{2}$, María Rocío Fernández-Santos ${ }^{1,3}$, Milagros C Esteso ${ }^{1,4}$, \\ Alejandro Maroto-Morales ${ }^{3}$, Olga García-Álvarez ${ }^{3}$ and J Julián Garde ${ }^{1}$ \\ ${ }^{1}$ Biology of Reproduction Group, National Wildlife Research Institute (IREC), CSIC-UCLM-JCCM, and Institute for \\ Regional Development (IDR), Ciencia y Tecnología Agroforestal, ETSIA, University of Castilla-La Mancha, Avenida de \\ España s/n, 02071 Albacete, Spain, ${ }^{2}$ Laboratorio de Teriogenología, CONICET-Universidad Nacional del Comahue, \\ 8303 Río Negro, Argentina, ${ }^{3}$ Regional Center of Animal Selection and Reproduction (CERSYRA), JCCM, Valdepeñas, \\ 13300 Ciudad Real, Spain and ${ }^{4}$ Molecular Biology, University of León, 24071 León, Spain
}

Correspondence should be addressed to F Martínez-Pastor; Email: felipe.martinez@uclm.es

\begin{abstract}
$\mathrm{Fe}^{2+}$ /ascorbate, hydrogen peroxide $\left(\mathrm{H}_{2} \mathrm{O}_{2}\right)$, and hypoxanthine/xanthine oxidase (XOD) are commonly used for inducing oxidative stress on spermatozoa. A comparative study of these agents was carried out on thawed spermatozoa from red deer. First, we tested a high, medium, and low concentration of each agent: 100, 10, and $1 \mu \mathrm{M} \mathrm{Fe}^{2+}$ (hydroxyl radical generator); $1 \mathrm{mM}, 100$, and $10 \mu \mathrm{M} \mathrm{H} \mathrm{H}_{2} ;$ and 100,10 , and $1 \mathrm{mU} / \mathrm{ml}$ XOD (superoxide and $\mathrm{H}_{2} \mathrm{O}_{2}$ generator), incubated at $37^{\circ} \mathrm{C}$ for $180 \mathrm{~min}$. Intracellular reactive oxygen species (ROS; $\mathrm{H}_{2}$ DCFDA) increased with dose and time similarly for the three systems at each concentration level. Motility and mitochondrial membrane potential $\left(\Delta \psi_{\mathrm{m}}\right)$ were considerably decreased by $\mathrm{H}_{2} \mathrm{O}_{2}(1 \mathrm{mM}$ and $100 \mu \mathrm{M})$ and XOD $(100$ and $10 \mathrm{mU} / \mathrm{ml})$. Only $1 \mathrm{mM} \mathrm{H} \mathrm{H}_{2}$ reduced viability. The antioxidant Trolox $(10 \mu \mathrm{M})$ reduced intracellular ROS, but could not prevent the $\mathrm{H}_{2} \mathrm{O}_{2}$ or XOD effects. In a second experiment, YO-PRO-1 and M540 were used as apoptotic and membrane stability markers respectively. Only $\mathrm{H}_{2} \mathrm{O}_{2}$ increased the proportion of apoptotic and membrane-destabilized spermatozoa. Catalase added to XOD prevented $\Delta \psi_{\mathrm{m}}$ loss, confirming that $\mathrm{H}_{2} \mathrm{O}_{2}$ was the causative agent, not superoxide. In a third experiment, caspase activation was tested using the (FAM-VAD-FMK) probe. Viable spermatozoa with activated caspases could be detected in untreated samples, and only $\mathrm{H}_{2} \mathrm{O}_{2}$ increased their proportion after 60 min. There were important differences between ROS generators, $\mathrm{H}_{2} \mathrm{O}_{2}$ being the most cytotoxic. Although $\mathrm{H}_{2} \mathrm{O}_{2}$ and $\mathrm{XOD}_{\text {caused }} \Delta \psi_{\mathrm{m}}$ dissipation, this was not reflected in increasing apoptotic markers.

Reproduction (2009) 137 225-235
\end{abstract}

\section{Introduction}

Oxidative stress has emerged as one of the major threats to sperm functionality, both in vivo and in vitro. Reactive oxygen species (ROS) have a fundamental role in sperm physiology (Aitken et al. 2004, O'Flaherty et al. 2006, de Lamirande \& O'Flaherty 2008), but their excess can damage spermatozoa (Shen \& Ong 2000, Aitken \& Baker 2002, Agarwal \& Saleh 2002, Agarwal et al. 2003). Concerning sperm work, ROS can be detrimental even within physiological levels, since they can trigger early capacitation and irreversible events such as acrosome reaction (Oehninger et al. 1995, Hsu et al. 1999, Satorre et al. 2007). Therefore, there is a great interest in protecting spermatozoa from ROS during manipulation and cryopreservation. To do this, researchers generally use external sources of ROS to study oxidative stress on spermatozoa. For instance, (hypo)xanthine/xanthine oxidase generates superoxide radical and hydrogen peroxide (Aitken et al. 1993), whereas ferrous ion/ ascorbate generates hydroxyl radical through the HaberWeiss or Fenton reaction (Buettner \& Jurkiewicz 1996). Hydrogen peroxide, a potent membrane-permeable oxidizing species, is often used directly (Oehninger et al. 1995, Hsu et al. 1999). However, few studies have aimed to compare the effects of different oxidant systems in spermatozoa, although this is of great interest, since different systems yield different ROS at different rates, thus causing possible variations in the effects and interactions with antioxidants. Thus, Kovalski et al. (1992) showed that hydrogen peroxide and the hydroxyl radical, but not the superoxide radical, inhibited the motility of human spermatozoa. The differential action of hydrogen peroxide and superoxide radical on human spermatozoa motility was also found by other authors (Aitken et al. 1993, Bilodeau et al. 2002). Armstrong et al. (1999) characterized the ROS production of activated leukocytes and the hypoxanthine/xanthine oxidase (XOD) system, and their effect on sperm motility and 
energetic metabolism. These authors found that hydrogen peroxide was not only responsible for the loss of motility, but also for the loss of mitochondrial membrane potential. However, these effects were not found when superoxide or hydroxyl radical - contrary to Kovalski et al. (1992) - was the predominant ROS.

Research on oxidative stress has converged with research on apoptosis in spermatozoa. Apoptotic markers have been found in spermatozoa of several species, but their role on sperm physiology is still not completely understood (Sakkas et al. 2002, Cayli et al. 2004, Lachaud et al. 2004, Paasch et al. 2004b, Barroso et al. 2006, Marti et al. 2006, Angelopoulou et al. 2007, Martin et al. 2007, Moran et al. 2008, Ortega-Ferrusola et al. 2008). The importance of ROS as apoptosis inducers and mediators has been demonstrated in somatic cells (Carmody \& Cotter 2001, Ott et al. 2007). It has been suggested that high ROS levels in semen might be associated with the presence of apoptotic markers (Wang et al. 2003, Moustafa et al. 2004), although a causative effect has yet to be demonstrated. In somatic cells, ROS (produced by the respiratory chain or externally) are among the inducers of type II apoptosis (also termed the intrinsic pathway; Carmody \& Cotter 2001, Owuor \& Kong 2002, Ott et al. 2007), and it has been shown that targeting antioxidants to the mitochondria can prevent the loss of $\Delta \psi_{\mathrm{m}}$ and apoptosis (Zhao et al. 2005). The intrinsic pathway is initiated in the mitochondria by the formation of the mitochondrial permeability transition pore, releasing components of the mitochondrial matrix, such as $\mathrm{Ca}^{2+}$ and cytochrome $c$ (Ott et al. 2007). Cytochrome $c$ induces the formation of the apoptosome, resulting in the activation of caspase 9, which subsequently activates caspase 3, a milestone event in apoptosis (Carmody \& Cotter 2001, Owuor \& Kong 2002). This intrinsic pathway of apoptosis may be present in spermatozoa, according to some studies (Paasch et al. 2004a, Wundrich et al. 2006, Bejarano et al. 2007, Martin et al. 2007). Previously, we proposed that the loss of $\Delta \psi_{\mathrm{m}}$ preceded plasmalemma destabilization as indicated by YO-PRO-1, suggesting an apoptotic-like phenomenon (Martinez-Pastor et al. 2008a). Therefore, we expected that ROS treatments causing $\Delta \psi_{\mathrm{m}}$ dissipation would elicit other apoptotic markers.

Considering these antecedents, and taking into account that most studies have been carried out on human spermatozoa, we aimed to analyze the effects of different oxidant systems in small ruminants, using red deer spermatozoa. Red deer is a relatively new farming species, which offers new opportunities for some kind of studies, since the variability of some traits (fertility, for instance) is still greater than that in other domestic species (Malo et al. 2005, Gomendio et al. 2006). In addition, studies on deer can be translated to different contexts (Garde et al. 2006): farming, hunting, and conservation (of endangered cervid species or populations). In this study, we analyzed the effect of incubating spermatozoa with different concentrations of the ferrous/ascorbate system (producing hydroxyl radicals), hydrogen peroxide, and XOD system (producing both superoxide and hydrogen peroxide). A commonly used antioxidant (Trolox, an analogue of $\alpha$-tocopherol) was tested against the oxidants to estimate which kind of effects could be abolished by a typical radical scavenger (Peña et al. 2003). Secondly, we evaluated the occurrence of apoptotic markers after incubation with these ROS generators, including the detection of activated caspases. According to previous studies, we hypothesized that part of the ROS effects may be mediated by apoptotic pathways, thus we tested the relationship between ROS presence, apoptotic markers, and other parameters of sperm quality.

\section{Results}

\section{Experiment 1: Motility, viability, and mitochondrial activity of spermatozoa exposed to different ROS sources}

The designs of the three experiments carried out in this study are illustrated in Fig. 1. The results of Experiment 1 for each oxidant are summarized in Fig. $2\left(\mathrm{Fe}^{2+} /\right.$ ascorbate), Fig. $3\left(\mathrm{H}_{2} \mathrm{O}_{2}\right)$, and Fig. 4 (HX/XOD). The incubation at $37^{\circ} \mathrm{C}$ with the ROS generators induced an increase in $\mathrm{H}_{2}$ DCFDA fluorescence, which was dependent on dose and incubation time, whereas control and Trolox did not show any significant variation. The concentrations of $1 \mathrm{mM}$ and $100 \mu \mathrm{M} \mathrm{H} \mathrm{H}_{2} \mathrm{O}_{2}$ (HP1000 and HP100) caused a quick increase in fluorescence signal with respect to control $(P<0.001)$ as soon as $15 \mathrm{~min}$ after starting incubation. However, at $1 \mathrm{~h}$ and $3 \mathrm{~h}$, fluorescence results were similar for the three ROS sources, XO100 yielding slightly lower values than FE100 and HP1000. The concentration of $10 \mathrm{mM}$ Trolox delayed ROS increase, dropping fluorescence intensity near to the lowest oxidant concentration in all cases (even lower than $1 \mathrm{mM} \mathrm{Fe}^{2+}, P<0.01$ at $3 \mathrm{~h}$ ). In contrast to the observed ROS increase, lipid peroxidation was only evident at $1 \mathrm{~h}$ for HP1000 $(P<0.001)$ and at 180 min for FE100 $(P<0.05), \mathrm{HP1000}$, and XO100 $(P<0.001)$. Again, Trolox reduced this increase, although it was still significantly different from control $(P<0.05)$.

Motility decreased steadily with incubation time in the control samples (slope $-0.15 \pm 0.02, P<0.001$, from an initial value of $51.25 \% \pm 2.96)$. The oxidant treatments affected motility in a very different manner. Thus, FE100 and FE10 induced an initial drop (at $15 \mathrm{~min}$ ) of $-12.08 \pm 2.88(P<0.01)$ and $-9.58 \pm 2.88(P<0.05)$ respectively, but these differences did not increase during the rest of the experiment (in fact, FE10 became not significantly different from control at 1 and $3 \mathrm{~h}$ ). In contrast, sperm motility index (SMI) dramatically 

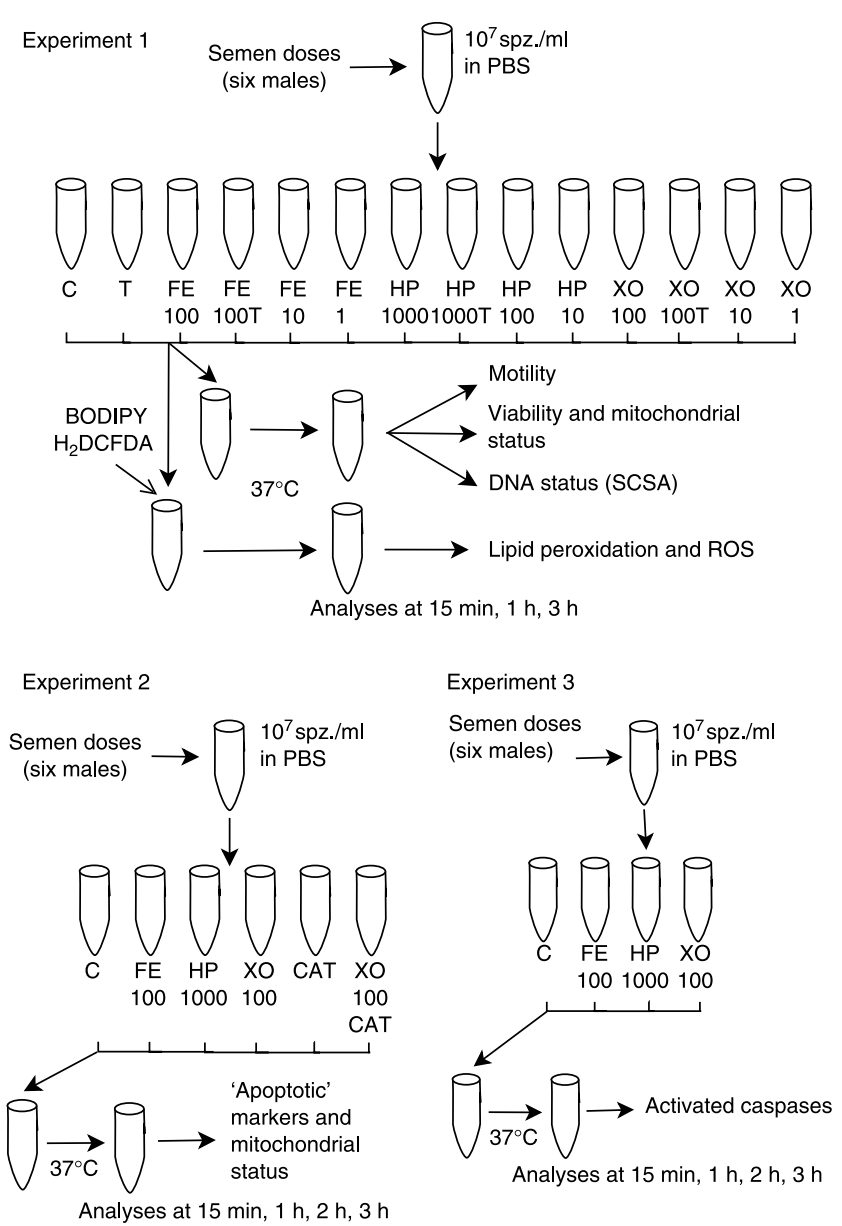

Figure 1 Schematic showing designs of the three experiments carried out in the present study. C, control (no treatment); FE100, $100 \mu \mathrm{M} \mathrm{Fe}^{2+}$ FE10, $10 \mu \mathrm{M} \mathrm{Fe}^{2+}$; FE1, $1 \mu \mathrm{M} \mathrm{Fe}^{2+}$; HP1000, $1 \mathrm{mM} \mathrm{H}_{2} \mathrm{O}_{2} ; \mathrm{HP} 100$, $100 \mu \mathrm{M} \mathrm{H}_{2} \mathrm{O}_{2}$; HP10, $10 \mu \mathrm{M} \mathrm{H}_{2} \mathrm{O}_{2}$; XO100, $100 \mathrm{mU} / \mathrm{ml}$ XOD; XO10, $10 \mathrm{mU} / \mathrm{ml}$ XOD; XO1, $1 \mathrm{mU} / \mathrm{ml}$ XOD. Antioxidant supplementation is indicated by $\mathrm{T}(10 \mu \mathrm{M}$ Trolox $)$ and CAT $(2500 \mathrm{U} / \mathrm{ml}$ catalase).

dropped in HP1000 $(-48.67 \pm 2.88$ at $15 \mathrm{~min}$, $P<0.001)$, not showing motile spermatozoa afterwards. HP100 caused a lower initial inhibition $(-15.00 \pm 2.88$ at $15 \mathrm{~min}, P<0.05)$. Nevertheless, motility was only $10.00 \% \pm 3.10$ at $1 \mathrm{~h}$, and motility inhibition was total at $3 \mathrm{~h}$. HP1 lowered motility at $15 \mathrm{~min}(-7.08 \pm 2.88$, $P<0.05)$, but it was not significantly different from control afterwards. HX/XOD decreased motility in a similar manner, but more slowly than $\mathrm{H}_{2} \mathrm{O}_{2}$. All XOD concentrations inhibited motility at 1 and $3 \mathrm{~h}$, but only XO100 affected motility significantly at $15 \mathrm{~min}$ $(-17.50 \pm 2.88, P<0.001)$. The effect of $\mathrm{XO} 1$ was relatively mild $(-7.92 \pm 2.53$ at $3 \mathrm{~h}, P<0.01)$, whereas inhibition was almost total at $3 \mathrm{~h}$ with $\mathrm{XO} 100$ and $\mathrm{XO} 10$ $(P<0.001)$. Trolox could not improve motility, neither in untreated samples nor when added to samples treated with oxidants. Only in the case of FE100, it partially prevented the motility decrease, and only at $15 \mathrm{~min}$.

The most striking difference between the oxidant systems was shown in the evaluation of mitochondrial
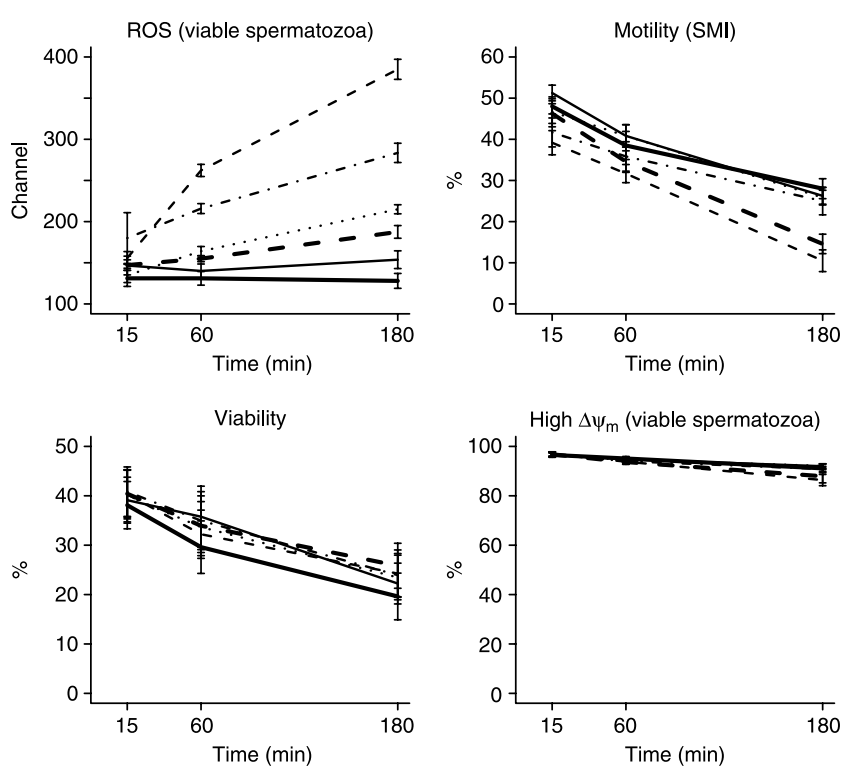

\begin{tabular}{|c|c|c|}
\hline & Control & - $\quad 100 \mu \mathrm{M} \mathrm{Fe}^{2+} /$ Trolox \\
\hline & Trolox & . $-10 \mu \mathrm{M} \mathrm{Fe} e^{2+}$ \\
\hline - & $100 \mu \mathrm{M} \mathrm{Fe} e^{2+}$ & . . $\quad 1 \mu \mathrm{M} \mathrm{Fe}^{2+}$ \\
\hline
\end{tabular}

Figure 2 Sperm parameters in the presence of different concentrations of $\mathrm{Fe}^{2+}$ (plus $100 \mu \mathrm{M}$ sodium ascorbate) and/or $10 \mu \mathrm{M}$ Trolox. ROS presence $\left(\mathrm{H}_{2} \mathrm{DCFDA}\right)$ is showed as the median fluorescence intensity of viable $(\mathrm{PI}-$ ) spermatozoa, whereas the rest of the parameters are percentages of motile, viable or viable + high- $\Delta \psi_{\mathrm{m}}$ spermatozoa. Model analyses are explained in the text. Data points are the mean \pm s.E.M. of six experiments.

membrane potential $\left(\Delta \psi_{\mathrm{m}}\right)$. Spermatozoa subjected to incubation with any $\mathrm{Fe}^{2+}$ concentration maintained high $\Delta \psi_{\mathrm{m}}$ while viable (all $\mathrm{PI}+$ spermatozoa had low $\Delta \psi_{\mathrm{m}}$ ), even after $180 \mathrm{~min}$ (control was $96.8 \% \pm 1.09$ at $15 \mathrm{~min}$ and $91.98 \% \pm 6.10$ at $3 \mathrm{~h}$, not being different from any $\mathrm{Fe}^{2+}$ treatment, $\left.P>0.46\right)$. In contrast, $\mathrm{H}_{2} \mathrm{O}_{2}$ and $\mathrm{HX} / \mathrm{XOD}$ showed a high-efficiency dissipating $\Delta \psi_{\mathrm{m}}$. At 60 min, both HP1000 and XO100 provoked a sharp drop in the percentage of viable spermatozoa with high $\Delta \psi_{\mathrm{m}}(-33.18 \pm 6.64$ and $-33.67 \pm 6.64$ from control respectively), abolishing it almost totally at $3 \mathrm{~h}$. HP100 showed the same effect, but only at $3 \mathrm{~h}(23.14 \% \pm 0.93)$. $\mathrm{XO} 10$ and XO1 affected $\Delta \psi_{\mathrm{m}}$, but only at $3 \mathrm{~h}$ $(59.31 \% \pm 13.36$ and $76.67 \% \pm 11.20$ respectively). Considering the median fluorescence intensity of Mitotracker (not shown in Fig. 4), there was a significant decrease in $\mathrm{H}_{2} \mathrm{O}_{2}$ and $\mathrm{HX} / \mathrm{XOD}$ treatments as soon as $15 \mathrm{~min}$. This lower fluorescence was observed in the high- $\Delta \psi_{\mathrm{m}}$ subpopulation at all times, even when it was not reflected in a significant drop of high- $\Delta \psi_{\mathrm{m}}$ spermatozoa. In contrast, $\mathrm{Fe}^{2+}$-treated samples had a median fluorescence intensity similar to control. The presence of Trolox did not improve neither the percentage of high- $\Delta \psi_{\mathrm{m}}$ spermatozoa nor the median fluorescence intensity.

Viability (membrane integrity) decreased in all treatments (slope $-0.11 \pm 0.02$ for control). Only HP1000 at 

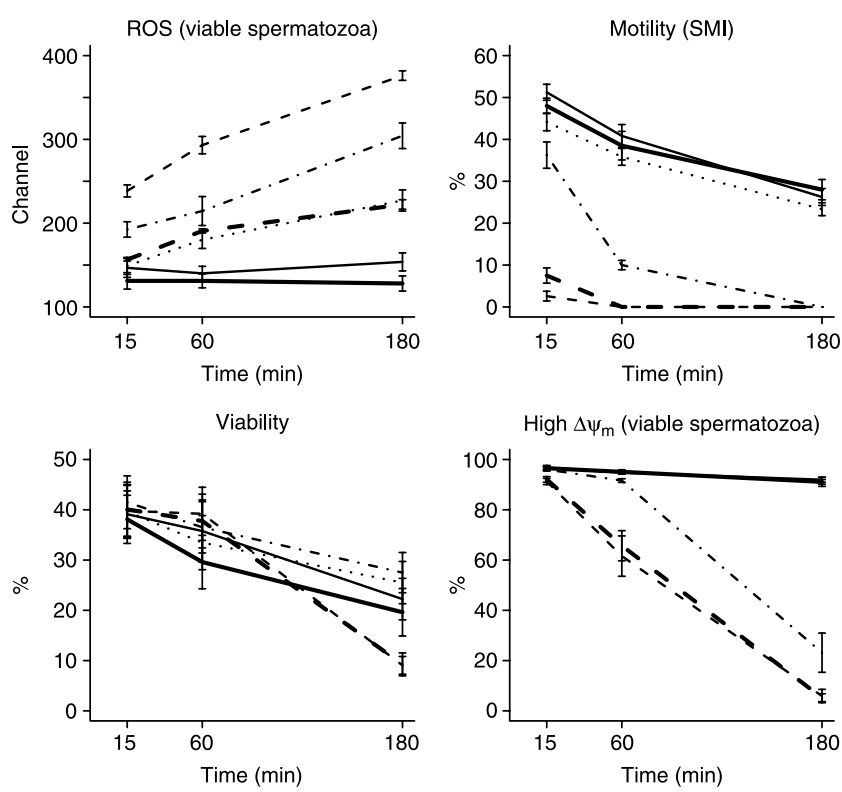

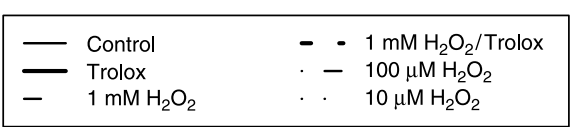

Figure 3 Sperm parameters in the presence of different concentrations of $\mathrm{H}_{2} \mathrm{O}_{2}$ and/or of $10 \mu \mathrm{M}$ Trolox. ROS presence $\left(\mathrm{H}_{2}\right.$ DCFDA) is showed as the median fluorescence intensity of viable ( $\mathrm{PI}-$ ) spermatozoa, whereas the rest of the parameters are percentages of motile, viable or high- $\Delta \psi_{\mathrm{m}}$ spermatozoa. Model analyses are explained in the text. Data points are the mean \pm S.E.M. of six experiments.

$180 \mathrm{~min}$ was significantly lower than control $(-13.18 \pm 3.05$ from a control value of $22.23 \% \pm 3.65$, $P<0.001)$, this decrease not being prevented by Trolox. Regarding chromatin status, we did not find any change from control. However, HDS was slightly higher for $\mathrm{HX} / \mathrm{XOD}$ than for control $(0.77 \% \pm 0.13)$ at $15 \mathrm{~min}$ $(2.82 \% \pm 0.26)$ and at $1 \mathrm{~h}(1.98 \% \pm 0.33)$, but not at $3 \mathrm{~h}$. Thus, these differences were probably not due to the effect of ROS on chromatin, but maybe to interferences of the HX/XOD treatment with the sperm chromatin structure assessment (SCSA) technique.

\section{Experiment 2: Induction of apoptotic/necrotic changes}

Labeling cells with the apoptotic marker YO-PRO-1 yielded three subpopulations: non-apoptotic (unstained), 'apoptotic' (YO-PRO-1+), and non-viable (membrane damaged, PI+; Martinez-Pastor et al. 2008a). As shown in Fig. 5, the proportion of non-apoptotic spermatozoa followed the same trend detected in Experiment 1 for viable spermatozoa, decreasing with time (slope $-0.075 \pm 0.01$ for control, $P<0.001$ ), and there were no differences between oxidants and control, except for $\mathrm{H}_{2} \mathrm{O}_{2}$ (slope $-0.12 \pm 0.01, P<0.05$ ). An apoptotic index was defined as the proportion of YO-PRO-1+ spermatozoa within the population of $\mathrm{PI}-$ spermatozoa. The model showed that the apoptotic index increased in
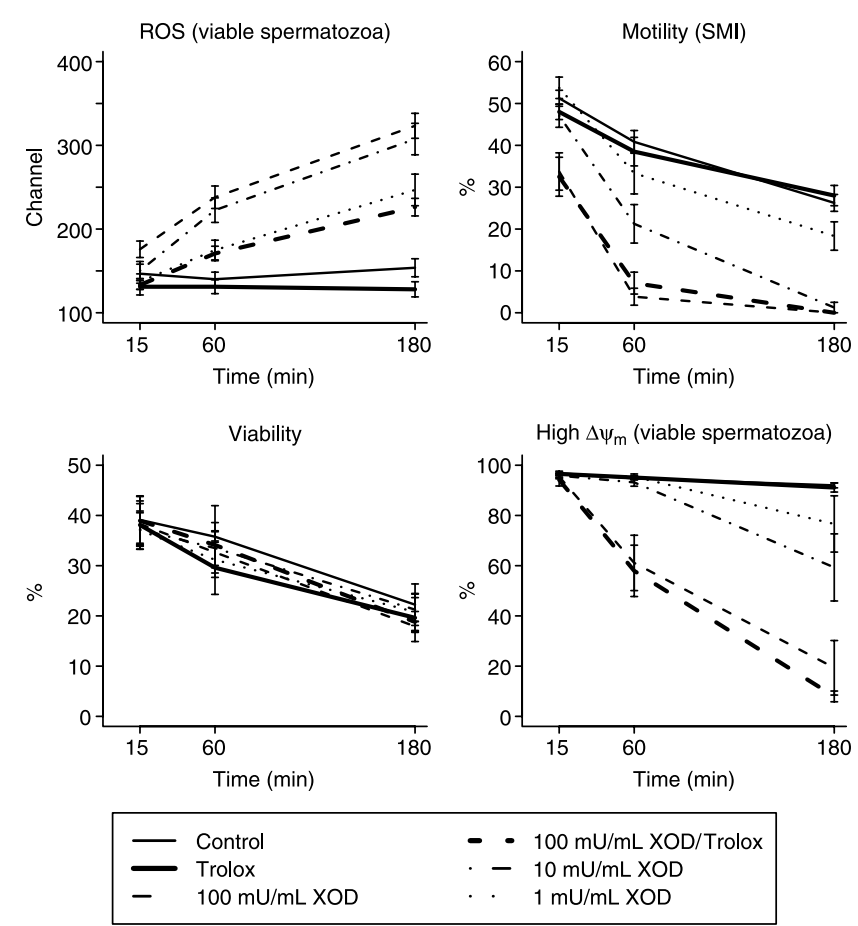

Figure 4 Sperm parameters in the presence of different concentrations of XOD (plus $100 \mu \mathrm{M}$ hypoxanthine), and two combinations of $10 \mu \mathrm{M}$ Trolox. ROS presence $\left(\mathrm{H}_{2}\right.$ DCFDA) is showed as the median

fluorescence intensity of viable ( $\mathrm{PI}-$ ) spermatozoa, whereas the rest of the parameters are percentages of motile, viable or high- $\Delta \psi_{\mathrm{m}}$ spermatozoa. Model analyses are explained in the text. Data points are the mean \pm s.E.M. of six experiments.

control (slope $0.07 \pm 0.02, P<0.01$ ), indicating that the decline in the YO-PRO-1 - population was caused not only by membrane damage $(\mathrm{PI}+)$, but also by 'apoptotic' changes in the membrane, resulting in a higher number of 'viable apoptotic' spermatozoa (YO-PRO- $1+/ \mathrm{PI}-$ ). $\mathrm{HX} / \mathrm{XOD}$ showed no difference from control, but $\mathrm{H}_{2} \mathrm{O}_{2}$ increased the slope of the model $(0.14 \pm 0.02, P<0.001)$, indicating an acceleration of the process. In contrast, $\mathrm{Fe}^{2+}$-treated samples stayed at the same level during the whole experiment. In this case, the reason was not that $\mathrm{Fe}^{2+}$ protected YO-PRO-1 - spermatozoa, but rather that YO-PRO-1 + spermatozoa were stained by PI + at a faster rate than in other treatments.

Another important difference between treatments was shown by the Merocyanine 540 (M540) staining. Only a very low proportion of YO-PRO-1 - spermatozoa fell in the high-M540 population (below $10 \%$ on average), except for $\mathrm{H}_{2} \mathrm{O}_{2}$-treated samples. In this case, the proportion of $\mathrm{M} 540+/ \mathrm{YO}-\mathrm{PRO}-1$ - spermatozoa increased up to $26.32 \% \pm 7.11$ at $2 \mathrm{~h}(P<0.001)$, without further increasing at $3 \mathrm{~h}$. The results for $\Delta \psi_{\mathrm{m}}$ were similar to those obtained in Experiment 1, although $\mathrm{H}_{2} \mathrm{O}_{2}$ was significantly different from control at $15 \mathrm{~min}$ $(-31.97 \pm 4.59, P<0.001)$.

Adding catalase to the sample treated with HX/XOD totally prevented $\Delta \psi_{\mathrm{m}}$ dissipation and motility 

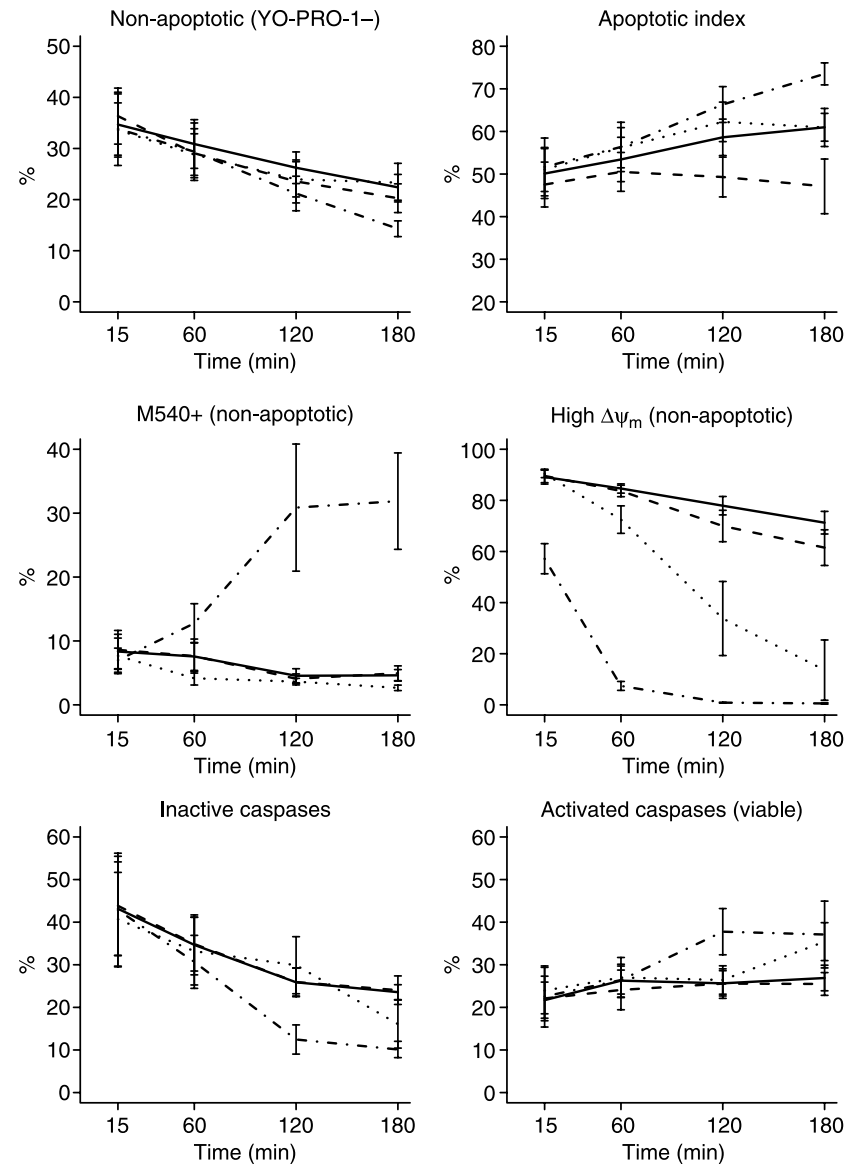

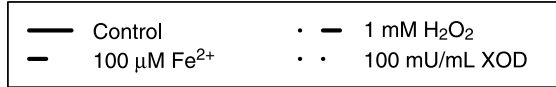

Figure 5 Change in different parameters during the incubation of spermatozoa with different oxidative agents. The apoptotic index is the proportion of 'apoptotic' (YO-PRO-1 +/PI - spermatozoa) taking the population of viable spermatozoa (PI-). For high $\Delta \psi_{\mathrm{m}}$ and Merocyanine 580 (M580), only the 'non-apoptotic' population (YO-PRO$1-$ ) was considered. For activated caspases, only the viable population $(\mathrm{PI}-)$ was considered. Model analyses are explained in the text. Data points are the mean \pm S.E.M. of six experiments.

inhibition. The results for control, catalase, and catalase $+\mathrm{HX} / \mathrm{XOD}$ treatments were very similar $(P>0.05)$, not only for $\Delta \psi_{\mathrm{m}}$, but also for membrane apoptotic markers (YO-PRO-1/PI).

\section{Experiment 3: The presence of activated caspases}

The analysis showed that all membrane-damaged spermatozoa $(\mathrm{PI}+)$ had activated caspases. The proportion of viable spermatozoa with inactive caspases (Fig. 5) decreased with incubation time in all cases (slope $-0.12 \pm 0.04$ for control, $P<0.01)$, and only $\mathrm{H}_{2} \mathrm{O}_{2}$ showed a lower proportion $(P<0.05$, except at $15 \mathrm{~h})$. However, the proportion of viable spermatozoa with active caspases stagnated at $25.88 \% \pm 1.13$, only increasing with time for $\mathrm{H}_{2} \mathrm{O}_{2}(P<0.05)$. Nevertheless, the $\mathrm{H}_{2} \mathrm{O}_{2}$ values did not increase any further after $120 \mathrm{~min}$, apparently reaching a plateau. HX/XOD showed an increase at $3 \mathrm{~h}$, which did not reach significance from control $(P=0.08)$.

\section{Discussion}

In this study, we compared the effects of the ROS generators $\mathrm{Fe}^{2+}$ /ascorbate, hydrogen peroxide, and XOD on red deer spermatozoa, as a model for small ruminants. Although the three systems differed greatly in their effects, they seemed to induce the same level of intracellular ROS. The 'low' concentrations noticeably increased the levels of ROS, but they did not lower sperm quality dramatically, contrary to the higher concentrations. This suggests that the concentrations in that magnitude could be used for increasing intracellular ROS while not reaching toxic levels, which might be useful in future studies. Nevertheless, two important facts should be taken into account on the nature of our samples while evaluating the results. First, cryopreserved samples were used. Cryopreservation not only reduces sperm quality, but also induces oxidative stress and decreases the antioxidants in semen (Aisen et al. 2005, Peris et al. 2007), therefore thawed spermatozoa could be more sensitive than fresh ones. Secondly, epididymal spermatozoa were used. The epididymal environment is not devoid of antioxidant systems (Vernet et al. 2004), but this protection is possibly lower than that conferred by seminal plasma, especially considering that prefreezing extension is much higher when handling epididymal samples than when diluting semen. Therefore, one must be careful when extrapolating these results not only to other species, but also to fresh or ejaculated spermatozoa.

Despite increasing intracellular $\mathrm{ROS}, \mathrm{Fe}^{2+}$ /ascorbate had little effects, whereas the 'medium' and 'high' concentrations of $\mathrm{H}_{2} \mathrm{O}_{2}$ and XOD greatly decreased sperm motility. Our results indicate that when combining HX/XOD and catalase, producing only the superoxide radical, motility was preserved. Thus, motility loss in red deer spermatozoa after oxidative stress seems to be caused by hydrogen peroxide, as previously reported in human semen (Aitken et al. 1993, Armstrong et al. 1999). In other studies (Kovalski et al. 1992, Chen et al. 1997), hydroxyl radical was found to affect motility similarly to hydrogen peroxide. These contrasting results could be explained by either hydrogen peroxide interference or experimental differences (species, techniques, etc.). The concurrent high levels of ROS $\left(\mathrm{H}_{2}\right.$ DCFDA fluorescence) yielded by $\mathrm{Fe}^{2+} /$ ascorbate, and its little effect on sperm motility or $\Delta \psi_{\mathrm{m}}$ observed in this study, could be explained taking into account the short life of the hydroxyl radical and its relative impermeability to biological membranes. Thus, it might readily oxidize $\mathrm{H}_{2}$ DCFDA in the cytoplasm, but its action on intracellular targets may be limited. 
Motility loss by hydrogen peroxide has been attributed to the inactivation of glycolytic enzymes, leading to energetic draining in the flagellum (Armstrong et al. 1999, Baumber et al. 2000). Our study seems to confirm that high doses of $\mathrm{H}_{2} \mathrm{O}_{2}$ cause an immediate inhibition of motility, which was almost total with $1 \mathrm{mM} \mathrm{H}_{2} \mathrm{O}_{2}$. The effect of xanthine oxidase was similar, but we observed a delay that might be explained considering that the enzymatic reaction could require some time to build up an equivalent amount of $\mathrm{H}_{2} \mathrm{O}_{2}$. It must be highlighted that mitochondrial activity was still high when motility had dropped. In another study (Martinez-Pastor et al. 2008a), we carried out an incubation without oxidants, noting that motility was much higher than the proportion of spermatozoa with high $\Delta \psi_{\mathrm{m}}$. Thus, the motility of deer spermatozoa seems to be independent - at least in the short term - of mitochondrial activity, similarly to human spermatozoa (Armstrong et al. 1999). ATP produced by mitochondria would not be transported to the flagellum efficiently enough to compensate for the depletion after the inactivation of glycolysis by hydrogen peroxide. In fact, the decrease in viability shown $3 \mathrm{~h}$ after applying the higher $\mathrm{H}_{2} \mathrm{O}_{2}$ dose could be a long-term effect of the lack of mitochondrial activity, as suggested previously (Martinez-Pastor et al. 2008a). Armstrong et al. (1999) found that treating human semen with $5 \mathrm{mM} \mathrm{H}_{2} \mathrm{O}_{2}$ dropped the percentage of high- $\Delta \psi_{\mathrm{m}}$ spermatozoa to $26 \%$ of control results in $30 \mathrm{~min}$, whereas only $0.3 \mathrm{mM}$ inhibited the motility of human spermatozoa in the same time. Similarly, Ramos \& Wetzels (2001) found an almost total loss of motility after a 5 min incubation of human spermatozoa with $25 \mu \mathrm{M} \mathrm{H}_{2} \mathrm{O}_{2}$. This might imply that small ruminant spermatozoa would be much more resilient, since $10 \mathrm{mM} \mathrm{H}_{2} \mathrm{O}_{2}$ showed no significant effect after $180 \mathrm{~min}$. Thus, the results obtained cannot be extrapolated to very different species. Baumber et al. (2000), testing a wide range of $\mathrm{H}_{2} \mathrm{O}_{2}$ concentrations on equine semen, obtained the results that resembled ours, although $12.5 \mathrm{mM} \mathrm{H}_{2} \mathrm{O}_{2}$ decreased motility significantly with respect to control after $180 \mathrm{~min}$. Interestingly, when we assessed DNA damage, we did not detect differences between treatments. In a previous experiment with bull semen (Fernandez-Santos et al. 2008, Martinez-Pastor et al. 2008b), we detected increased DNA damage using SCSA, after subjecting thawed spermatozoa to oxidative stress. The lack of differences in the present study could be due to species or treatment differences $(6 \mathrm{~h}$ of incubation). Peris et al. (2007) reported that SCSA showed differences between different $\mathrm{H}_{2} \mathrm{O}_{2}$ treatments $(0-300 \mu \mathrm{M})$ in ram semen, but only after $24 \mathrm{~h}$ incubation, and not after $4 \mathrm{~h}$.

The antioxidant Trolox seemed to successfully decrease the intracellular ROS level of the 'high' concentration (although not down to control levels), but it could not prevent the negative effects of hydrogen peroxide and HX/XOD, except lowering membrane lipoperoxidation. Trolox could have been particularly efficient in protecting lipids and other molecules from oxidation (such as $\mathrm{H}_{2} \mathrm{DCFDA}$ ), but it failed in protecting other kind of targets, such as sulphydryl groups on proteins. We did not test other antioxidants (except catalase, in Experiment 2), but other studies have suggested that glutathione, for instance, had a protective effect on motility when $\mathrm{H}_{2} \mathrm{O}_{2}$ was present (Baumber et al. 2000), and studies on other cell types have identified glutathione and other compounds as mitochondrial protectors (Fernandez-Gomez et al. 2005, Hardeland 2005). In a previous study, we found that catalase could improve deer spermatozoa cryopreservation better than other antioxidants (Fernandez-Santos et al. 2007b), which agrees with our findings in this work (nevertheless, we did not assess apoptotic markers). Nonetheless, we have to take into account that we chose Trolox in this experiment because of its ubiquity among other studies, and because we wanted a 'generic', instead of a specific (superoxide dismutase, catalase, and DMSO), antioxidant.

We hypothesized that ROS and antioxidants could influence the occurrence of apoptotic markers in red deer spermatozoa through $\Delta \psi_{\mathrm{m}}$ dissipation, as shown previously in human semen (Paasch et al. 2004a, Wundrich et al. 2006, Bejarano et al. 2007, Martin et al. 2007), and we showed that the loss of $\Delta \psi_{\mathrm{m}}$ may precede changes conducing to $\mathrm{YO}-\mathrm{PRO}-1$ labeling (Martinez-Pastor et al. 2008a). In the present study, $1 \mathrm{mM}$ and $100 \mu \mathrm{M} \mathrm{H}_{2} \mathrm{O}_{2}$ caused a dramatic loss of $\Delta \psi_{\mathrm{m}}$, but this was not accompanied by a similar increase of other apoptotic markers, either based on membrane destabilization (apoptotic index, YO-PRO-1) or on the detection of activated caspases (FLICA). Although hydrogen peroxide increased the apoptotic index and the proportion of viable spermatozoa with activated caspases (with respect to control), suggesting some degree of caspase activation, this increase should have been much larger (nearly affecting most spermatozoa at $60 \mathrm{~min}$ ) if the loss of $\Delta \psi_{\mathrm{m}}$ effectively initiated apoptotic pathways. Furthermore, $\mathrm{HX} / \mathrm{XOD}$, which yielded $\mathrm{H}_{2} \mathrm{O}_{2}$, could not elicit a significant increase in these parameters. Nevertheless, in Experiment 2, there was a delay of $\Delta \psi_{\mathrm{m}}$ dissipation by HX/XOD when compared with hydrogen peroxide, thus its effect could have been similar if longer times had been tried. Unfortunately, we could not test caspase activation when we combined HX/XOD and catalase, to study the superoxide effect specifically. However, we did not note differences concerning YO-PRO-1/PI labeling. Considering the similarities among the apoptotic index in Experiment 2 and caspase activation in Experiment 3, it seems that caspase activation might not occur with the superoxide radical alone.

As indicated in the introduction, the presence of functional apoptotic pathways is a controversial issue in spermatozoa. Nevertheless, apoptotic markers can be detected, and the possibility that they might have an 
effect on sperm fate should not be discarded (Paasch et al. 2004a, Wundrich et al. 2006, Bejarano et al. 2007, Martin et al. 2007). Based on our results, it is possible that $\mathrm{H}_{2} \mathrm{O}_{2}$ would induce at least some elements of apoptotic pathways, but only in a reduced subpopulation of spermatozoa, as suggested previously (Weng et al. 2002). The plateau reached after $60 \mathrm{~min}$ by the proportion of viable spermatozoa with activated caspases seems to support this idea, suggesting that a large proportion of spermatozoa were unable to show apoptotic markers in response to oxidative stress by $\mathrm{H}_{2} \mathrm{O}_{2}$. Another plateau was found when plotting the percentage of YO-PRO-1 - spermatozoa stained by Merocyanine 540, supporting the previous suggestion (Martinez-Pastor et al. 2008a) that YO-PRO-1 staining might be preceded by another kind of membrane changes. Muratori et al. (2004) indicated that Merocyanine 540 would stain cells with early membrane degeneration. In our study, it is likely that Merocyanine 540 was related to decreasing membrane lipid packaging associated with membrane destabilization, but it cannot be confirmed in this study.

These findings suggest - as a hypothesis for future studies - that apoptotic markers (such as caspase activation and YO-PRO-1 staining) would occur only in a subpopulation of spermatozoa. Previous studies seem to support this idea. Paasch et al. (2004a) and Grunewald et al. (2005) detected an increase in activated caspases after applying betulinic acid (an activator of the apoptotic intrinsic pathway) to human spermatozoa. Recently, Moran et al. (2008) showed that both betulinic acid and nitric oxide increased YO-PRO$1+/ \mathrm{PI}-$ spermatozoa in boar semen. These increases (either activated caspases or YO-PRO-1+/PI-) only affected part of the spermatozoa, just as we detected in the $\mathrm{H}_{2} \mathrm{O}_{2}$ treatment. The confirmation of this kind of subpopulations would represent a breakthrough finding, since many separation and evaluation methods for spermatozoa rely on the detection of apoptotic markers (such as phosphatidylserine externalization; Grunewald et al. 2006). Alternatively, if these pathways were involved in sperm DNA damage (by the activation of endogenous endonucleases; Gorczyca et al. 1993, Lamond et al. 2003), caspase inhibitors (Eley et al. 2005, Marti et al. 2008) or mitochondrial protectors (Lamond et al. 2003, Fernandez-Gomez et al. 2005, Hardeland 2005) might improve artificial reproductive techniques. In this study, we did not find an increase in DNA damage as shown by the SCSA, but other techniques (such as oxidized bases detection; Shen \& Ong 2000) might be more sensitive. Nevertheless, Moran et al. (2008) found that nitric oxide caused caspase activation in almost all viable spermatozoa, whereas, contrary to findings in human sperm, betulinic acid could not increase activated caspases. This indicates that the activation of apoptotic markers, and its consequences, may depend on species and inductors.
In conclusion, our results show clear differences among ROS generators. Hydrogen peroxide was cytotoxic to red deer spermatozoa, in agreement with results in other species. This does not mean that superoxide and hydroxyl radicals had no effect, only that their effect was not evident on the studied traits. Taking into account that oxidant levels were chosen according to similar $\mathrm{H}_{2}$ DCFDA fluorescence levels, factors such as half-life or membrane permeability only partly explain the observed differences. In fact, superoxide and hydroxyl radicals may trigger physiological pathways, disqualifying spermatozoa for further use. Moreover, only $\mathrm{H}_{2} \mathrm{O}_{2}$ seemed to cause an increase in apoptotic markers, and it seems that sperm subpopulations differing on its ability to display these markers may exist. Another interesting observation is the presence of activated caspases in red deer thawed spermatozoa, even in the absence of treatment. These results suggest future lines of work to improve sperm work in red deer and, possibly, small ruminants.

\section{Materials and Methods}

\section{Reagents and media}

Fluorescence probes and the Vybrant FAM Poly Caspases Assay Kit were purchased from Invitrogen. Acridine orange (chromatographically purified) was purchased from Polysciences Inc. (Warrington, PA, USA). Flow cytometry equipment, software, and consumables (including the sheath fluid) were purchased from BD Biosciences (San José, CA, USA). The rest of the chemicals were acquired from Sigma. Chemicals were of reagent grade or higher. PBS was prepared in milli-Q water: $136.9 \mathrm{mM} \mathrm{NaCl}, 2.7 \mathrm{mM} \mathrm{KCl}, 0.9 \mathrm{mM} \mathrm{CaCl}, 0.5 \mathrm{mM}$ $\mathrm{MgCl}_{2}, 7 \mathrm{mM} \mathrm{Na} \mathrm{HPO}_{4}, 1.25 \mathrm{mM} \mathrm{NaH} \mathrm{PO}_{4}, 1.5 \mathrm{mM}$ $\mathrm{KH}_{2} \mathrm{PO}_{4}$, and $\left.1 \mathrm{~g} / \mathrm{l} \mathrm{PVA} \mathrm{(290} \mathrm{mOsm/kg;} \mathrm{pH} 7.2\right)$. Hypoxanthine was prepared at $200 \mathrm{mM}$ in $0.1 \mathrm{M} \mathrm{NaOH}$. Stock solutions of the antioxidant and oxidants were as follows: Trolox (vitamin E), $1 \mathrm{mM}$ in ethanol; $\mathrm{H}_{2} \mathrm{O}_{2}, 100 \mathrm{mM}$ in water; $\mathrm{XOD}, 10 \mathrm{UI} / \mathrm{ml}$ in water; $\mathrm{Fe}^{2}$ /ascorbate, $10 \mathrm{mM} \mathrm{FeSO}_{4}$ and $100 \mathrm{mM}$ sodium ascorbate in water. From each oxidant solution, $1 / 10$ and $1 / 100$ solutions were prepared in water. Stock solutions of the fluorescence probes were as follows: propidium iodide, $7.5 \mathrm{mM}$ in water; SYBR-14, $1 \mathrm{mM}$ in DMSO; Mitotracker Deep Red, $1 \mathrm{mM}$ in DMSO; BODIPY $\mathrm{C}_{11} 665 / 676,0.1 \mathrm{mM}$ in DMSO; $\mathrm{H}_{2}$ DCFDA, $0.5 \mathrm{mM}$ in DMSO. All solutions were kept at $-20{ }^{\circ} \mathrm{C}$ and in the dark until needed, except Trolox and the oxidant working solutions, which were prepared the same day. Preparation and staining of samples for flow cytometry analysis were performed by flow cytometer PBS (BD FACSFlow; BD Biosciences).

\section{Semen cryopreservation}

Epididymal samples were collected from mature stags (Cervus elaphus hispanicus; Helzheimer 1909) that were legally culled and hunted in their natural habitat during the rutting season (September-October). Hunting was in accordance with the 
harvest plan of game reserves, following Spanish Harvest Regulation (Law 2/93 of Castilla-La Mancha), which conforms to European Union Regulations. These operations were carried out as part of a project approved by the ethical committee of the University of Castilla-La Mancha, and which adheres to the Guidelines for the Care and Use of Animals. Spermatozoa were collected from the cauda epididymis within $3 \mathrm{~h}$ postmortem, and diluted to $200 \times 10^{6}$ spermatozoa/ml in Triladyl (Minitüb, Tifenbach, Germany) with $20 \%$ egg yolk and $6 \%$ glycerol. After $2 \mathrm{~h}$ of equilibration at $5{ }^{\circ} \mathrm{C}$, samples were loaded into $0.25 \mathrm{ml}$ plastic straws (IMV, L'Aigle Cedex, France) and frozen in nitrogen vapor ( $4 \mathrm{~cm}$ above liquid nitrogen) for $10 \mathrm{~min}$. The straws remained for a minimum period of 1 year in liquid nitrogen. Thawing was carried out by immersing straws in a water bath at $37^{\circ} \mathrm{C}$ for $30 \mathrm{~s}$.

\section{Experiment 1}

This experiment evaluated the effect of oxidative stress on sperm motility, viability, mitochondrial membrane potential $\left(\Delta \psi_{\mathrm{m}}\right)$, intracellular ROS, and membrane lipid peroxidation. It was replicated using samples from six different males. Thawed semen was resuspended to $10^{7}$ spermatozoa/ml with PBS. The sperm solution was then split among 14 aliquots in microtubes. One of them was left untreated as control (C), and another one was supplemented with $10 \mu \mathrm{M}$ Trolox (T). The other aliquots were subjected to oxidative stress using three concentrations of each oxidant system. For $\mathrm{Fe}^{2+}$ /ascorbate: $100 \mu \mathrm{M} \mathrm{Fe} \mathrm{Fe}^{2+}$ (FE100), $10 \mu \mathrm{M} \mathrm{Fe}^{2+}$ (FE10), and $1 \mu \mathrm{M} \mathrm{Fe}^{2+}$ (FE1); for $\mathrm{H}_{2} \mathrm{O}_{2}$ : $1 \mathrm{mM}$ (HP1000), $100 \mu \mathrm{M}$ (HP100), and $10 \mu \mathrm{M}$ (HP10); and for HX/XOD: $100 \mathrm{mU} / \mathrm{ml}$ XOD (XO100), $10 \mathrm{mU} / \mathrm{ml}$ XOD (XO10), and $1 \mathrm{mU} / \mathrm{ml} X O D(X O 1)$. The highest concentration of each oxidant was replicated, supplementing this replication with $10 \mu \mathrm{M}$ Trolox (FE100T, HP1000T, and XO100T). The aliquots with XOD received $2 \mathrm{mM}$ hypoxanthine and $1 \mathrm{mM}$ EDTA. All the treatments were split into two aliquots. One of them received $0.5 \mu \mathrm{M} \mathrm{H}_{2}$ DCFDA and $0.2 \mu \mathrm{M}$ BODIPY $\mathrm{C}_{11} 665 / 676$ (for the detection of intracellular ROS and membrane lipoperoxidation respectively). The microtubes were incubated at $37^{\circ} \mathrm{C}$ in the dark and analyzed at 15,60 , and 180 min after starting the incubation. The three concentrations for each system were selected after a preliminary assay using $\mathrm{H}_{2}$ DCFDA, in order to obtain similar 'low', 'medium', and 'high' production of ROS in each system.

Motility was subjectively assessed. A $5 \mu$ drop was placed on a prewarmed slide, covered with a coverslip and examined using a phase contrast microscope (Nikon Eclipse 80i; negative contrast optics), with a warming stage at $37^{\circ} \mathrm{C}$. A sperm motility index (SMI) was calculated (Fernandez-Santos et al. 2007a), assessing the percentage of motile sperm (MI) and the quality of movement (QM; from 0 , no motility to 5, fast and lineal motility), and using the formula $S M I=(M I+20 \times Q M) \times$ 0.5 . The same skilled evaluator was in charge of assessing all samples.

Sperm viability and $\Delta \psi_{\mathrm{m}}$ (SYBR-14/propidium iodide (PI) and Mitotracker Deep Red), and intracellular ROS and membrane lipid peroxidation $\left(\mathrm{H}_{2}\right.$ DCFDA and BODIPY $\mathrm{C}_{11}$ $665 / 676$ ) were assessed by flow cytometry. For the analysis of viability and $\Delta \psi_{\mathrm{m}}$, we diluted the spermatozoa down to
$10^{6} / \mathrm{ml}$ in flow cytometry PBS with $10 \mu \mathrm{M}$ SYBR-14, $24 \mu \mathrm{M} \mathrm{PI}$, and $100 \mathrm{nM}$ Mitotracker Deep Red. For the analysis of intracellular ROS and membrane lipid peroxidation, the prelabeled samples were diluted down to $10^{6} / \mathrm{ml}$ in flow cytometry PBS with $5 \mu \mathrm{M}$ PI. In both stainings, the samples were left $15 \mathrm{~min}$ in the dark before running them through a flow cytometer.

Moreover, an aliquot of each sample was diluted in TNE buffer $(0.15 \mathrm{M} \mathrm{NaCl}, 0.01 \mathrm{M}$ Tris $\mathrm{HCl}, 1 \mathrm{mM}$ EDTA; $\mathrm{pH}$ 7.4) to $2 \times 10^{6} / \mathrm{ml}$ in cryotubes for chromatin assessment (SCSA). The cryotubes were flash-frozen in liquid nitrogen and stored at $-80{ }^{\circ} \mathrm{C}$ until analysis (see below).

\section{Experiment 2}

This experiment evaluated the expression of apoptosis/necrosis markers after exposure to oxidative stress. It was replicated using samples from six different males. Thawed semen was resuspended to $10^{7}$ spermatozoa $/ \mathrm{ml}$ with $\mathrm{PBS}$. The sperm solution was then split among four aliquots in microtubes. One of them was left untreated as control, and the others were subjected to oxidative stress: $\mathrm{Fe}^{2+}$ /ascorbate $\left(100 \mu \mathrm{M} \mathrm{Fe}^{2+}\right)$, $\mathrm{H}_{2} \mathrm{O}_{2}(1 \mathrm{mM})$, and HX/XOD $(100 \mu \mathrm{M}$ XOD, $2 \mathrm{mM}$ hypoxanthine, and $1 \mathrm{mM}$ EDTA). The microtubes were incubated at $37^{\circ} \mathrm{C}$. At $15 \mathrm{~min}, 1 \mathrm{~h}, 2 \mathrm{~h}$, and $3 \mathrm{~h}$, the samples were diluted down to $10^{6} / \mathrm{ml}$ in flow cytometry PBS with $5 \mu \mathrm{M}$ Hoechst 33342, 100 nM YO-PRO-1, $1 \mu \mathrm{M}$ Merocyanine 540, $10 \mu \mathrm{M} \mathrm{PI}$, and $100 \mathrm{nM}$ Mitotracker Deep Red. After $15 \mathrm{~min}$ in the dark, the samples were run through a flow cytometer. YO-PRO- 1 is a probe capable of staining early apoptotic cells, with intact plasmalemma (not stained by $\mathrm{Pl}$, for instance), but showing increased permeability (typical of early apoptotic cells; Martinez-Pastor et al. 2008a). Merocyanine 540 is a lipophilic probe that increases its fluorescence as membrane lipid packaging decreases, being useful for assessing membrane stability and, possibly, capacitation-related events (FernandezSantos et al. 2007a).

To confirm that $\mathrm{H}_{2} \mathrm{O}_{2}$ was the causative agent of $\Delta \psi_{\mathrm{m}}$ dissipation, two more treatments were added: $2500 \mathrm{U} / \mathrm{ml}$ catalase and HX/XOD plus $2500 \mathrm{U} / \mathrm{ml}$ catalase. Thus, the $\mathrm{H}_{2} \mathrm{O}_{2}$ resulting from XOD or superoxide dismutation was removed. Incubation and analysis were performed in the same way as for the other treatments of the experiments.

\section{Experiment 3}

In this experiment, we assessed the presence of activated caspases after exposure to ROS. The samples were prepared in the same manner as in Experiment 2 and incubated at $37^{\circ} \mathrm{C}$. At $15 \mathrm{~min}, 1 \mathrm{~h}, 2 \mathrm{~h}$, and $3 \mathrm{~h}$, the samples were processed to evaluate caspase activation using the Vybrant FAM Poly Caspases Assay Kit. This kit is based on the fluorescent caspase inhibitor (FAM-VAD-FMK), which binds to active caspases, thus labeling apoptotic cells. Briefly, the aliquots were diluted down to $10^{6} / \mathrm{ml}$ in $300 \mu \mathrm{l}$ of PBS with $10 \mu \mathrm{l}$ of 30X FLICA reagent (fluorescent caspase inhibitor) in flow cytometry tubes. The tubes were incubated for $1 \mathrm{~h}$ at $37^{\circ} \mathrm{C}$ in the dark and then washed twice with the washing buffer provided by the kit 
(300 g, $5 \mathrm{~min}$ ). After the second centrifugation, the washing buffer was replaced by $400 \mu$ l of the flow cytometer sheath fluid with $5 \mu \mathrm{M}$ Hoechst 33342 and $10 \mu \mathrm{M} \mathrm{PI}$. After $15 \mathrm{~min}$ in the dark, the samples were run through a flow cytometer.

\section{Flow cytometer configuration}

For flow cytometry, a Becton Dickinson LSR-I model (BD Biosciences) was used. A $488 \mathrm{~nm}$ Ar-ion laser was used for exciting SYBR-14, YO-PRO-1, FLICA, PI, Merocyanine 580, and $\mathrm{H}_{2}$ DCFDA, and a $633 \mathrm{~nm}$ He-Ne laser for exciting Mitotracker Deep Red and BODIPY $C_{11}$ 665/676. Fluorescence from SYBR-14, YO-PRO-1, FLICA, Merocyanine 540, and $\mathrm{H}_{2}$ DCFDA was read with the $\mathrm{FL} 1$ photodetector (530/28BP filter). Fluorescence from Merocyanine 540 was read with the FL2 photodetector (575/25BP filter). Fluorescence from PI was read with the FL3 photodetector (670LP filter). Fluorescence from TO-PRO-1, Mitotracker Deep Red, and BODIPY $\mathrm{C}_{11} 665 / 676$ was read with the FL6 photodetector (670/40BP filter). FSC/SSC signals were used to discriminate spermatozoa from debris. When Hoechst 33342 was used, it was excited using a $350 \mathrm{~nm}$ He-Cd laser, and its fluorescence was read with the FL5 photodetector (424/44BP filter). The FL5 signal was used to improve spermatozoa/debris discrimination. Fluorescence captures were controlled using the Cell Quest Pro 3.1 software (BD Biosciences). All the parameters were read using logarithmic amplification. For each sample, 10000 spermatozoa were recorded, saving the data in FCS v. 2 files. The analysis of the flow cytometry data was carried out using WinMDI v. 2.8 (The Scripps Research Institute, La Jolla, CA, USA).

\section{Sperm chromatin structure assessment}

The SCSA technique (Evenson et al. 2002) is based on the metachromatic stain acridine orange, which fluoresces green when combined with double-stranded DNA, and red when combined with single-stranded DNA (denatured). The samples flash-frozen in TNE were thawed on crushed ice and $200 \mu \mathrm{l}$ were transferred to a flow cytometry tube. Then, $400 \mu \mathrm{l}$ of cold acid-detergent solution $(0.08 \mathrm{M} \mathrm{HCl}, 0.15 \mathrm{M} \mathrm{NaCl}, 0.1 \%$ Triton $\mathrm{X}-100 ; \mathrm{pH} 1.2)$ were added. Exactly $30 \mathrm{~s}$ after adding the aciddetergent solution, $1.2 \mathrm{ml}$ of cold staining solution $(6 \mu \mathrm{g} / \mathrm{ml}$ of acridine orange in a buffer containing $37 \mathrm{mM}$ citric acid, $126 \mathrm{mM} \mathrm{Na} \mathrm{HPO}_{4}, 1.1 \mathrm{mM}$ disodium EDTA, and $150 \mathrm{mM}$ $\mathrm{NaCl}$; $\mathrm{pH}$ 6) were added. After $3 \mathrm{~min}$, the sample was run through the flow cytometer. Acridine orange was excited using the Ar-ion laser $(488 \mathrm{~nm})$. The red fluorescence was detected using the FL3 photodetector (670LP) and the green fluorescence using the FL1 photodetector (530/28BP). In both cases, linear scales were used. The cytometer was previously equilibrated using a tube with $0.4 \mathrm{ml}$ of acid-detergent solution and $1.2 \mathrm{ml}$ of staining solution. This tube was run regularly between samples to diminish changes due to flow variations (Boe-Hansen et al. 2005). The data acquisition was controlled using the Cell Quest Pro 3.1 software, acquiring 5000 spermatozoa, and the data were processed using WinMDI v. 2.8. We calculated the DNA fragmentation index (DFI) for each spermatozoa as the ratio of red fluorescence with respect to total fluorescence (red + green), expressed as a percentage. The processing of DFI data was performed by the $\mathrm{R}$ statistical environment ( $R$ Development Core Team 2007). From the DFI values, the standard deviation of DFI (SD-DFI) was obtained, as well as the percentage of spermatozoa with high fragmentation index $(\% \mathrm{DFI})$ and the percentage of spermatozoa with high DNA stainability (HDS), defined as those events with green fluorescence above channel 600.

\section{Data processing and statistical analysis}

The $\mathrm{R}$ statistical environment was used to process flow cytometry data and to perform subsequent statistical analysis. Our hypotheses were tested using mixed-effects linear models, treating the replication as a random effect. Despite individual differences, the samples from different males behaved similarly, and an interference of male with treatment was discarded. Pairwise comparisons were carried out using contrasts and Holm's correction for multiple comparisons. Numerical results were expressed as mean \pm S.E.M.

\section{Declaration of interest}

The authors declare that there is no conflict of interest that could be perceived as prejudicing the impartiality of the research reported.

\section{Funding}

This work has been supported by the Spanish Ministry of Science and Innovation (grant number AGL2004-05904/GAN) and by the Education and Science Council of Junta de Comunidades de Castilla-La Mancha (grant number PAC060047). F Martínez-Pastor, M C Esteso, and M R FernándezSantos were supported by the Juan de la Cierva program (Spanish Ministry of Science and Innovation). O GarcíaÁlvarez and A Maroto-Morales were recipients of a scholarship from INIA and Junta de Comunidades de Castilla-La Mancha (Spain) respectively. E Aisen was supported by a travel grant from the University of Castilla-La Mancha (Spain).

\section{Acknowledgements}

The authors would like to thank Álvaro E Domínguez and Enrique del Olmo for their help in the flow cytometry analysis, and Juan F Llopis, Juani Ronzal, and the Regional Center for Biomedical Research (UCLM; Albacete, Spain) for providing the flow cytometry equipment and assistance.

\section{References}

Agarwal A \& Saleh RA 2002 Role of oxidants in male infertility: rationale, significance, and treatment. Urologic Clinics of North America 29 817-827.

Agarwal A, Saleh RA \& Bedaiwy MA 2003 Role of reactive oxygen species in the pathophysiology of human reproduction. Fertility and Sterility $\mathbf{7 9}$ 829-843. 
Aisen E, Quintana M, Medina V, Morello H \& Venturino A 2005 Ultramicroscopic and biochemical changes in ram spermatozoa cryopreserved with trehalose-based hypertonic extenders. Cryobiology $50239-249$.

Aitken RJ \& Baker MA 2002 Reactive oxygen species generation by human spermatozoa: a continuing enigma. International Journal of Andrology 25 191-194.

Aitken RJ, Buckingham D \& Harkiss D 1993 Use of a xanthine oxidase free radical generating system to investigate the cytotoxic effects of reactive oxygen species on human spermatozoa. Journal of Reproduction and Fertility 97 441-450.

Aitken RJ, Ryan AL, Baker MA \& McLaughlin EA 2004 Redox activity associated with the maturation and capacitation of mammalian spermatozoa. Free Radical Biology \& Medicine 36 994-1010.

Angelopoulou R, Plastira K \& Msaouel P 2007 Spermatozoal sensitive biomarkers to defective protaminosis and fragmented DNA. Reproductive Biology and Endocrinology 536.

Armstrong JS, Rajasekaran M, Chamulitrat W, Gatti P, Hellstrom WJ \& Sikka SC 1999 Characterization of reactive oxygen species induced effects on human spermatozoa movement and energy metabolism. Free Radical Biology \& Medicine 26 869-880.

Barroso G, Taylor S, Morshedi M, Manzur F, Gavino F \& Oehninger S 2006 Mitochondrial membrane potential integrity and plasma membrane translocation of phosphatidylserine as early apoptotic markers: a comparison of two different sperm subpopulations. Fertility and Sterility 85 149-154.

Baumber J, Ball B, Gravance C, Medina V \& Davies-Morel M 2000 The effect of reactive oxygen species on equine sperm motility, viability, acrosomal integrity, mitochondrial membrane potential, and membrane lipid peroxidation. Journal of Andrology 21 895-902.

Bejarano I, Lozano G, Ortiz A, Garcia J, Paredes S, Rodriguez A \& Pariente J 2007 Caspase 3 activation in human spermatozoa in response to hydrogen peroxide and progesterone. Fertility and Sterility 90 1340-1347.

Bilodeau JF, Blanchette S, Cormier N \& Sirard MA 2002 Reactive oxygen species-mediated loss of bovine sperm motility in egg yolk tris extender: protection by pyruvate, metal chelators and bovine liver or oviductal fluid catalase. Theriogenology 57 1105-1122.

Boe-Hansen GB, Ersboll AK \& Christensen P 2005 Variability and laboratory factors affecting the sperm chromatin structure assay in human semen. Journal of Andrology 26 360-368.

Buettner GR \& Jurkiewicz BA 1996 Catalytic metals, ascorbate and free radicals: combinations to avoid. Radiation Research 145 532-541.

Carmody RJ \& Cotter TG 2001 Signalling apoptosis: a radical approach. Redox Report 6 77-90.

Cayli S, Sakkas D, Vigue L, Demir R \& Huszar G 2004 Cellular maturity and apoptosis in human sperm: creatine kinase, caspase-3 and Bcl-XL levels in mature and diminished maturity sperm. Molecular Human Reproduction 10 365-372.

Chen CS, Chao HT, Pan RL \& Wei YH 1997 Hydroxyl radical-induced decline in motility and increase in lipid peroxidation and DNA modification in human sperm. Biochemistry and Molecular Biology International 43 291-303.

Eley A, Hosseinzadeh S, Hakimi H, Geary I \& Pacey AA 2005 Apoptosis of ejaculated human sperm is induced by co-incubation with Chlamydia trachomatis lipopolysaccharide. Human Reproduction 20 2601-2607.

Evenson DP, Larson KL \& Jost LK 2002 Sperm chromatin structure assay: its clinical use for detecting sperm dna fragmentation in male infertility and comparisons with other techniques. Journal of Andrology $2325-43$.

Fernandez-Gomez FJ, Galindo MF, Gomez-Lazaro M, Yuste VJ, Comella JX, Aguirre N \& Jordan J 2005 Malonate induces cell death via mitochondrial potential collapse and delayed swelling through an rosdependent pathway. British Journal of Pharmacology 144 528-537.

Fernandez-Santos MR, Martinez-Pastor F, Garcia-Macias V, Esteso MC, Soler AJ, de Paz P, Anel L \& Garde JJ 2007a Extender osmolality and sugar supplementation exert a complex effect on the cryopreservation of Iberian red deer (Cervus elaphus hispanicus) epididymal spermatozoa. Theriogenology 67 738-753.

Fernandez-Santos MR, Martinez-Pastor F, Garcia-Macias V, Esteso MC, Soler AJ, Paz P, Anel L \& Garde JJ 2007 b Sperm characteristics and DNA integrity of Iberian red deer (Cervus elaphus hispanicus) epididymal spermatozoa frozen in the presence of enzymatic and nonenzymatic antioxidants. Journal of Andrology 28 294-305.

Fernandez-Santos M, Dominguez-Rebolledo A, Esteso M, Garde J \& Martinez-Pastor F 2008 Catalase supplementation on thawed bull spermatozoa abolishes the detrimental effect of oxidative stress on motility and DNA integrity. International Journal of Andrology [in press] DOI: 10.1111/j.1365-2605.2008.00871.x.

Garde J, Martinez-Pastor F, Gomendio M, Malo A, Soler A, FernandezSantos M, Esteso M, Garcia A, Anel L \& Roldan E 2006 The application of reproductive technologies to natural populations of red deer. Reproduction in Domestic Animals 41 93-102.

Gomendio M, Malo AF, Soler AJ, Fernandez-Santos MR, Esteso MC, Garcia AJ, Roldan ERS \& Garde J 2006 Male fertility and sex ratio at birth in red deer. Science 314 1445-1447.

Gorczyca W, Traganos F, Jesionowska H \& Darzynkiewicz Z 1993 Presence of DNA strand breaks and increased sensitivity of DNA in situ to denaturation in abnormal human sperm cells: analogy to apoptosis of somatic cells. Experimental Cell Research 207 202-205.

Grunewald S, Paasch U, Said TM, Sharma RK, Glander HJ \& Agarwal A 2005 Caspase activation in human spermatozoa in response to physiological and pathological stimuli. Fertility and Sterility 83 1106-1112.

Grunewald S, Paasch U, Said TM, Rasch M, Agarwal A \& Glander HJ 2006 Magnetic-activated cell sorting before cryopreservation preserves mitochondrial integrity in human spermatozoa. Cell and Tissue Banking 7 99-104.

Hardeland R 2005 Antioxidative protection by melatonin: multiplicity of mechanisms from radical detoxification to radical avoidance. Endocrine 27 119-130.

Hsu PC, Hsu CC \& Guo YL 1999 Hydrogen peroxide induces premature acrosome reaction in rat sperm and reduces their penetration of the zona pellucida. Toxicology 139 93-101.

Kovalski NN, de Lamirande E \& Gagnon C 1992 Reactive oxygen species generated by human neutrophils inhibit sperm motility: protective effect of seminal plasma and scavengers. Fertility and Sterility 58 809-816.

Lachaud C, Tesarik J, Canadas ML \& Mendoza C 2004 Apoptosis and necrosis in human ejaculated spermatozoa. Human Reproduction 19 607-610.

de Lamirande E \& O'Flaherty C 2008 Sperm activation: role of reactive oxygen species and kinases. Biochimica et Biophysica Acta $\mathbf{1 7 8 4}$ $106-115$

Lamond S, Watkinson M, Rutherford T, Laing K, Whiting A, Smallwood A, Nargund G, Campbell S \& Banerjee S 2003 Gene-specific chromatin damage in human spermatozoa can be blocked by antioxidants that target mitochondria. Reproductive Biomedicine Online 7 407-418.

Malo A, Garde J, Soler A, García A, Gomendio M \& Roldan E 2005 Male fertility in natural populations of red deer is determined by sperm velocity and the proportion of normal spermatozoa. Biology of Reproduction 72 822-829.

Marti E, Perez-Pe R, Muino-Blanco T \& Cebrian-Perez JA 2006 Comparative study of four different sperm washing methods using apoptotic markers in ram spermatozoa. Journal of Andrology 27 746-753.

Marti E, Perez-Pe R, Colas C, Muino-Blanco T \& Cebrian-Perez JA 2008 Study of apoptosis-related markers in ram spermatozoa. Animal Reproduction Science 106 113-132.

Martin G, Cagnon N, Sabido O, Sion B, Grizard G, Durand P \& Levy R 2007 Kinetics of occurrence of some features of apoptosis during the cryopreservation process of bovine spermatozoa. Human Reproduction 22 380-388.

Martinez-Pastor F, Fernandez-Santos MR, del Olmo E, DominguezRebolledo AE, Esteso MC, Montoro V \& Garde JJ 2008a Mitochondrial activity and forward scatter vary in necrotic, apoptotic and membraneintact spermatozoan subpopulations. Reproduction, Fertility, and Development 20 547-556.

Martinez-Pastor F, Fernandez-Santos MR, Dominguez-Rebolledo A, Esteso M \& Garde JJ 2008b DNA status on thawed semen from fighting bull: a comparison between the SCD and the SCSA tests. Reproduction in Domestic Animals [in press] DOI: 10.1111/j.1439-0531.2008.01098.x.

Moran JM, Madejon L, Ortega Ferrusola C \& Pena FJ 2008 Nitric oxide induces caspase activity in boar spermatozoa. Theriogenology 70 91-96. 
Moustafa MH, Sharma RK, Thornton J, Mascha E, Abdel-Hafez MA, Thomas AJJ \& Agarwal A 2004 Relationship between ros production, apoptosis and dna denaturation in spermatozoa from patients examined for infertility. Human Reproduction 19 129-138.

Muratori M, Porazzi I, Luconi M, Marchiani S, Forti G \& Baldi E 2004 Annexin $\mathrm{V}$ binding and merocyanine staining fail to detect human sperm capacitation. Journal of Andrology 25 797-810.

Oehninger S, Blackmore P, Mahony M \& Hodgen G 1995 Effects of hydrogen peroxide on human spermatozoa. Journal of Assisted Reproduction and Genetics 12 41-47.

O'Flaherty C, de Lamirande E \& Gagnon C 2006 Positive role of reactive oxygen species in mammalian sperm capacitation: triggering and modulation of phosphorylation events. Free Radical Biology \& Medicine 41 528-540.

Ortega-Ferrusola C, Sotillo-Galan Y, Varela-Fernandez E, GallardoBolanos JM, Muriel A, Gonzalez-Fernandez L, Tapia JA \& Pena FJ 2008 Detection of 'apoptosis-like' changes during the cryopreservation process in equine sperm. Journal of Andrology 29 213-221.

Ott M, Gogvadze V, Orrenius S \& Zhivotovsky B 2007 Mitochondria, oxidative stress and cell death. Apoptosis 12 913-922.

Owuor ED \& Kong ANT 2002 Antioxidants and oxidants regulated signal transduction pathways. Biochemical Pharmacology 64 765-770.

Paasch U, Grunewald S, Dathe S \& Glander HJ 2004a Mitochondria of human spermatozoa are preferentially susceptible to apoptosis. Annals of the New York Academy of Sciences 1030 403-409.

Paasch U, Sharma RK, Gupta AK, Grunewald S, Mascha EJ, Thomas AJJ, Glander HJ \& Agarwal A 2004b Cryopreservation and thawing is associated with varying extent of activation of apoptotic machinery in subsets of ejaculated human spermatozoa. Biology of Reproduction $7 \mathbf{1}$ 1828-1837.

Peña F, Johannisson A, Wallgren M \& Rodriguez Martinez H 2003 Antioxidant supplementation in vitro improves boar sperm motility and mitochondrial membrane potential after cryopreservation of different fractions of the ejaculate. Animal Reproduction Science 78 85-98.

Peris SI, Bilodeau JF, Dufour M \& Bailey JL 2007 Impact of cryopreservation and reactive oxygen species on dna integrity, lipid peroxidation, and functional parameters in ram sperm. Molecular Reproduction and Development 74 878-892.
R Development Core Team 2007 R: A Language and Environment for Statistical Computing, Vienna, Austria: R Foundation for Statistical Computing.

Ramos L \& Wetzels AM 2001 Low rates of DNA fragmentation in selected motile human spermatozoa assessed by the TUNEL assay. Human Reproduction 16 1703-1707.

Sakkas D, Moffatt O, Manicardi GC, Mariethoz E, Tarozzi N \& Bizzaro D 2002 Nature of dna damage in ejaculated human spermatozoa and the possible involvement of apoptosis. Biology of Reproduction $\mathbf{6 6}$ 1061-1067.

Satorre MM, Breininger E, Beconi MT \& Beorlegui NB $2007 \boldsymbol{\alpha}$-Tocopherol modifies tyrosine phosphorylation and capacitation-like state of cryopreserved porcine sperm. Theriogenology 68 958-965.

Shen H \& Ong C 2000 Detection of oxidative dna damage in human sperm and its association with sperm function and male infertility. Free Radical Biology \& Medicine 28 529-536.

Vernet P, Aitken RJ \& Drevet JR 2004 Antioxidant strategies in the epididymis. Molecular and Cellular Endocrinology 216 31-39.

Wang X, Sharma RK, Sikka SC, Thomas AJJ, Falcone T \& Agarwal A 2003 Oxidative stress is associated with increased apoptosis leading to spermatozoa DNA damage in patients with male factor infertility. Fertility and Sterility 80 531-535.

Weng SL, Taylor SL, Morshedi M, Schuffner A, Duran EH, Beebe S \& Oehninger S 2002 Caspase activity and apoptotic markers in ejaculated human sperm. Molecular Human Reproduction 8 984-991.

Wundrich K, Paasch U, Leicht M \& Glander HJ 2006 Activation of caspases in human spermatozoa during cryopreservation-an immunoblot study. Cell and Tissue Banking 7 81-90.

Zhao K, Luo G, Giannelli S \& Szeto H 2005 Mitochondria-targeted peptide prevents mitochondrial depolarization and apoptosis induced by tertbutyl hydroperoxide in neuronal cell lines. Biochemical Pharmacology 70 1796-1806.

Received 18 August 2008

First decision 18 September 2008

Revised manuscript received 31 October 2008

Accepted 21 November 2008 